\title{
An ISO 25010 Based Quality Model for ERP Systems
}

\author{
Emmanuel Peters ${ }^{1, *}$, George Kwamina Aggrey ${ }^{2}$ \\ ${ }^{1}$ Computer Science and Information Technology, Accra Institute of Technology, P.O.Box AN 19782, Accra-North, Ghana \\ ${ }^{2}$ Computer Science and Information Technology, University of Cape Coast, P.O. Box PMB, Cape Coast, Ghana
}

A R T I C L E I N F O

Article history:

Received: 01 November, 2019

Accepted: 07 January, 2020

Online: 10 April, 2020

Keywords:

ERP systems

Software Quality Model

ERP systems Quality Model

ISO 25010 Model

\begin{abstract}
A B S T R A C T
Higher Education Institutions (HEIs) have begun rapidly adopting, selecting and implementing ERP systems due to the call by various governments to streamline their processes and practices. While ERPs are expanding at much faster rate, there is pressure on most HEIs to ensure quality. For quality model, ISO/IEC 25010 is an international standard for software and systems quality evaluation. With the introduction of three specific new sub-factors, this paper presents a new model based on the ISO/IEC 25010 for the evaluation of quality enterprise resource planning (ERP) systems. This new model can be used to select and adopt ERP systems in higher education institutions. It can also serve as a guide in implementing ERP systems in higher education institutions. The new model comprises eight factors which include functional suitability, reliability, usability, performance efficiency, compatibility, security, maintainability and portability. These eight quality factors are further divided into thirty-four (34) sub-factors. Thus, the outcome of this study is a model developed for quality evaluation of ERP systems in HEIs.
\end{abstract}

\section{Introduction}

ERP systems are designed to allow smooth and easy flow of information across functional areas of an institution or organization. They are made to address problems of information disjointments or "Islands of information" in organizations. Enterprise resource planning (ERP) systems have been introduced into higher educational institutions to integrate and computerize most of the business operations which include recruitment, admission, financial aid, student records, and most academic and administrative services [1]. According to [2], ERP systems have several advantages in HEIs: (1) improved information access for planning and managing institutional resources; (2) faculty, students and employees get improved services; (3) reduced business risks and (4) income and expenditure improved efficiently. By implementing such systems, HEIs are expected to improve quality and productivity of their operations. Due to these advantages, many higher education institutions have spent time, money and effort in the implementation of ERP systems [3].

The market of ERP systems is expected to reach $\$ 41.69$ billion in sales by 2020 [4]. However, studies have shown that there are challenges in the selection and implementation of ERP systems especially among higher education institutions. Studies about educational institution's information systems have all been about

${ }^{*}$ Emmanuel Peters, Email: peterse30@gmail.com

Www.astesj.com

https://dx.doi.org/10.25046/aj050272 e-book systems [5] and e-learning websites [6], thereby ignoring the ERP systems. Several software and systems quality models [5], $[7,8]$ have been developed to evaluate the quality of ERP systems in HEIs, but none of these has adapted the ISO 25010 as their base model. It is therefore, necessary to adapt this international standard (ISO 25010) which has been in existence since 2011, for quality evaluation of ERP systems in HEIs.

The study seeks to refine and extend the quality model of ISO 25010. Since ISO 25010 extends and refines the ISO 9126, there is the need to extend and refine the existing quality models of ERP systems in HEIs. Based on the ISO 25010, this paper presents a new model for quality ERP systems evaluation in HEIs since models are not static.

\section{Literature Review}

Several quality models in the literature were developed for software and systems evaluations. Thus, ERP systems selection and adoption in higher education would require a careful adaptation. This section gives the highlights on two popular software and systems quality models in the literature, their advantages and disadvantages. Based on these two models, we then propose an appropriate software quality model for ERP systems in HEIs. These two popular software and systems quality models are ISO 9126 and ISO 25010 quality models. 


\subsection{ISO 9126 Model}

ISO 9126 is an international standard for software quality evaluation. It was originally presented in 1991 and fully adapted in 1992. The ISO 9126 quality model addresses three aspects of software quality which are; the internal quality, the external quality and the quality in use [9]. ISO 9126 model therefore, evaluates the quality of software product based on the external, internal and quality in use attributes. The quality attributes are presented as a hierarchical structure of factors and sub-factors. The highest level comprises of six factors that are further decomposed into twenty one (21) sub-factors on the lowest level. ISO 9126 a derivation of McCall's model expresses 21 sub-attributes that every quality software product must exhibit. According to [9] the ISO 9126 model comprises of the following four part standards:

- ISO/IEC 9126-1 (ISO/IEC, 2001a): This standard defines an updated quality model.

- ISO/IEC 9126-2 (ISO/IEC, 2003a): This standard defines a set of external metrics.

- ISO/IEC 9126-3 (ISO/IEC, 2003b): This standard defines a set of internal metrics.

- ISO/IEC 9126-4 (ISO/IEC, 2001b): This standard defines a set of quality in use metrics.

\subsection{ISO 25010 Model}

ISO 25010 is an international standard for software and systems quality evaluation. This standard has gone through three important updates in 2007, 2011 and 2017 [10]. This standard is also known as the SQuaRE (Systems and software Quality Requirements and Evaluation) model. It describes software product quality and quality in use as well. According to [10] ISO 25010 was developed from an update of ISO 9126 model. According to them, the previous model (ISO 9126) has six (6) factors and twenty-one (21) sub-factors. By simple comparison of the two models, "security" and "compatibility" were the only two factors introduced together with their sub-factors into the ISO 25010. The quality attributes in this model are presented starting from top factors down to the sub-factors. The top level composes eight factors that are further decomposed into thirty one (31) subfactors on the down level. ISO 25010 a derivation of ISO 9126 model describes thirty-one (31) attributes that every quality software product must exhibit.

Many researchers [11 - 13] have adapted the ISO 25010 standard to propose new quality models in their studies. As an international standard, the ISO 25010 model has also been adapted in this study to develop new ERP systems quality model.

\section{New ERP System Quality Model}

Even though there are specific software quality models developed for specific software products evaluations, majority of software quality models are general and common for all types of software products. For instance, ISO 25010 has factors which are general for evaluating quality of every type of system and software products. Moreover, many systems and software products have their own factors or features which must be considered during evaluation. Therefore, for an evaluation of software and systems products, the existing software quality models should be carefully selected, modified or extended. This means the quality factors and sub-factors of a quality model should be adjusted to fit or match the new system being evaluated and not the vice versa. Thus, this study adapts the ISO 25010 to assess quality of ERP systems in HEIs.

Although, there are several researches on quality of software products based on ISO 9126 model in education environments [5, 6] studies on adapting ISO 25010 model to evaluate ERP systems in HEIs are very rare. Thus, the novelty about this study is the proposed quality model based on ISO 25010 for ERP systems quality evaluations in HEIs. Even though ISO 9126 has been used severally in developing other models to evaluate ERP systems, this new ISO 25010 model has also been developed to improve, replace and extend it. Since systems and software products are becoming increasingly complex and sophisticated nowadays, new quality models are also needed to evaluate them. Therefore, quality models based on the ISO 25010 are needed to evaluate ERP systems in HEIs.

Many researchers [11 - 13] have adapted the ISO 25010 in their studies. The generality of ISO 25010 quality model makes it easy to be adapted into developing many specific software quality models such as the ERP systems quality model. In adapting models like ISO 25010, researchers would mostly eliminate some quality attributes or factors, add new attributes or redefine the existing attributes of the model. This study adds and redefines the subfactors of the ISO 25010 in order to suite a quality model for ERP systems evaluations in HEIs. The new ERP system quality model describes eight (8) factors including functional suitability, reliability, usability, performance efficiency, compatibility, security, maintainability and portability which are further decomposed into thirty four (34) sub-factors. Three new subfactors have been introduced into the ISO 25010 model in this study. Supportability and searchability have been added as subfactors under usability and archivability has also been added as a sub-factor under security. The section that follows describes the three new sub-factors, existing factors and sub-factors of the ISO 25010 model adapted for this study.

\subsection{Definition and Justification of the three new sub-factors}

Supportability: This feature can be defined as the ability of the system or software to provide certain basic needs to its users. It is the extent to which a software or system can assist its users in completing basic tasks. In higher education institutions (HEIs), most of the users of the ERP systems are not ICT trained experts therefore; they will need certain supports from the system in order to complete most of their tasks. They would need certain instructional programs and hints to be able to accomplish these basic tasks. ERP systems are huge systems which must include all these instructional programs and hints to enable its users to use them comfortably. Therefore, supportability is added as a subfactor under usability factor.

Searchability: This feature of a system or software defines the capability of a software or a system to quickly find or obtain information from its database. It is the degree at which software or system can quickly find or obtain its information. Again, ERP systems are huge information systems that can store large information about organizations and institutions. Information 


\section{E. Peters et al. / Advances in Science, Technology and Engineering Systems Journal Vol. 5, No. 2, 578-583 (2020)}

about students, teaching and non-teaching staffs and administrative processes can be stored by these systems. For that matter, ERP systems must include features or tools that will assist its users in finding information quickly. For this reason, searchability is also added as a sub-factor under usability factor.

Archivability: Archivability feature or factor of a system can be defined as the set of tools or techniques of a system used in preserving or reserving information for future reference. In other words, it is the extent to which a system can preserve its information for future references. For instance, in higher education institutions, it is mandatory to preserve outgoing students' records for future references. It is important therefore, to employ ERP systems that can preserve and reserve students' records for future references. Based on this reason, archivability is added as a subfactor under security factor.

\subsection{Functional Suitability}

This quality factor describes the extent to which a software product or system provides functions that satisfy the stated and implied needs of stakeholders when used under specified conditions [14]. This quality factor has been divided into three lower-factors including functional completeness, functional correctness and functional appropriateness [12, 14]. Since ERP systems in HEIs come with various functional applications, there must be a quality factor such as functional suitability to help evaluate these functions. Hence, functional suitability has been adapted in the new ERP system quality model.

\subsection{Reliability}

Reliability factor expresses the capability of a system or software product to maintain its level of performance or specified functions under specified conditions for a specified time period. Four lower-factors are associated to reliability factor namely maturity, availability, fault tolerance and recoverability [13, 14]. This quality factor has been adapted in our new ERP system quality model to assess the reliability of various functions and services that ERP systems provide in HEIs under certain stated conditions.

\subsection{Usability}

According to [14] usability factor describes the extent to which software or system product can be used to achieve specified goals with effectiveness, efficiency and satisfaction in a specified context of use. The usability factor has set of lower-factors which include appropriateness recognizability, learnability, operability, user error protection, user interface aesthetics and accessibility [13]. In this study, supportability and searchability were added as lower-factors under usability to help evaluate the operations of ERP systems in HEIs. Since usability is an important quality factor to every software or systems that include ERP systems, it has been adapted in our new ERP system quality model.

\subsection{Performance Efficiency}

The performance efficiency factor describes the ability of software product or system in managing the given amount of resources to provide and maximize performance [14]. This quality factor has also been decomposed into three lower-factors including time behaviour, resource utilization and capacity [12]. Performance efficiency has been adapted into the new ERP system quality model to assess the resource allocation and use of the ERP systems when providing required services and functions in HEIs.

\subsection{Compatibility}

Compatibility factor is the capability of the software products or system to interact with other software products or systems without any glitches. That is the ERP system performs its required functions while sharing the same hardware or software environments with other systems. Compatibility factor has two lower-factors namely co-existence and interoperability [13, 14]. Again, adapting this quality factor in the new ERP system quality model will assist the evaluation of information exchange and sharing of common environment by the ERP system with other software products and systems.

\subsection{Security}

According to [14] security factor is about how the software products or systems protect its information and data (information resources) from unauthorized persons or from other software products or systems. The security factor comes with set of lowerfactors which include confidentiality, integrity, non-repudiation, accountability and authenticity $[12,14]$. In this study, archivability has been added as a lower-factor under security to evaluate the operations of ERP systems in HEIs. Since security is an important quality factor to every software or systems that include ERP systems, it has been adapted into our new ERP system quality model.

\subsection{Maintainability}

The ability of software products or systems to be modified, corrected, or adapted to current changes in the environment describes its maintainability feature. Five lower-factors including modularity, reusability, analyzability, modifiability and testability were associated to maintainability [11]. Applying this quality factor to the new ERP system quality model will suggest that the ERP systems in HEIs should permit modifications or corrections without much difficulty.

\subsection{Portability}

The ability of software products or systems to be transferred from one hardware, software or other operational or usage environment to another operational platform defines its portability feature [14]. Three lower-factors including adaptability, installability and replaceability describe portability feature [12]. This quality factor has been adapted into the new ERP system quality model to evaluate ERP systems operations in different hardware and software platforms and across different environments.

In the light of all the analysis done in this study, Table 1 and Figure 1 present the new quality model based on the ISO 25010 standard. This new quality model includes the eight (8) main factors and thirty-four (34) sub-factors. The proposed model shows how these quality factors and sub-factors have been adapted to evaluate the quality of ERP systems in HEIs. 
Table 1: ERP System quality model in HEIs

\begin{tabular}{|c|c|c|}
\hline Factor & Sub-Factor & Explanation \\
\hline \multirow{3}{*}{ Functional Suitability } & Functional completeness & Does ERP system cover all specified tasks and user objectives? \\
\hline & Functional correctness & $\begin{array}{l}\text { Can ERP system provide correct results with the needed degree } \\
\text { of precision? }\end{array}$ \\
\hline & Functional appropriateness & $\begin{array}{l}\text { Does ERP system's function facilitate the accomplishment of } \\
\text { specified tasks and objectives? }\end{array}$ \\
\hline \multirow[t]{4}{*}{ Reliability } & Maturity & $\begin{array}{l}\text { Does ERP system meet the needs of its users under normal } \\
\text { operations? }\end{array}$ \\
\hline & Availability & $\begin{array}{l}\text { Can the ERP system be operational and accessible at a time } \\
\text { needed for use? }\end{array}$ \\
\hline & Fault tolerance & $\begin{array}{l}\text { Can the ERP system operate as planned despite the malfunction } \\
\text { hardware or software existence? }\end{array}$ \\
\hline & Recoverability & $\begin{array}{l}\text { During a disaster, can ERP system recover and re-establish the } \\
\text { system to its desired state? }\end{array}$ \\
\hline \multirow[t]{8}{*}{ Usability } & Appropriateness recognizability & $\begin{array}{l}\text { Can ERP system be easily recognized by users as an } \\
\text { appropriate product or system to solve their needs? }\end{array}$ \\
\hline & Learnability & Can ERP system be learnt more easily? \\
\hline & Operability & Can ERP system be easily operated and controlled? \\
\hline & User error protection & Does the ERP system protect users against making errors? \\
\hline & User interface aesthetics & $\begin{array}{l}\text { Does the ERP system user interface look pleasant and } \\
\text { satisfactory? }\end{array}$ \\
\hline & Accessibility & $\begin{array}{l}\text { Can the ERP system be accessed by specified users under } \\
\text { specified conditions? }\end{array}$ \\
\hline & Supportability & $\begin{array}{l}\text { Can the ERP system provide basic operational instructions and } \\
\text { hints to its users when in operation? }\end{array}$ \\
\hline & Searchability & $\begin{array}{l}\text { Can information be easily searched, found or located with the } \\
\text { ERP system? }\end{array}$ \\
\hline \multirow[t]{3}{*}{ Performance Efficiency } & Time behaviour, & Can ERP system response and process events faster? \\
\hline & Resource utilization & Can ERP system utilize information resources efficiently? \\
\hline & Capacity & Do ERP system parameters meet their system requirements? \\
\hline \multirow[t]{2}{*}{ Compatibility } & Co-existence & $\begin{array}{l}\text { Can the ERP system perform its required operations efficiently } \\
\text { while sharing its environment and information resources with } \\
\text { other products or systems? }\end{array}$ \\
\hline & Interoperability & $\begin{array}{l}\text { Can ERP system interact with other systems or software } \\
\text { products? }\end{array}$ \\
\hline \multirow[t]{6}{*}{ Security } & Confidentiality & $\begin{array}{l}\text { Can ERP system ensure that information resources are } \\
\text { accessible only to those authorized to have access? }\end{array}$ \\
\hline & Integrity & $\begin{array}{l}\text { Does ERP system prevent unauthorized access to information } \\
\text { resources or modification of data? }\end{array}$ \\
\hline & Non-repudiation & $\begin{array}{l}\text { Can the ERP system prove an action or an event believed to } \\
\text { have taken place? }\end{array}$ \\
\hline & Accountability & $\begin{array}{l}\text { Can the ERP system uniquely trace or account for an action or } \\
\text { event of an entity? }\end{array}$ \\
\hline & Authenticity & Can the ERP system be used to identify its users and resources? \\
\hline & Archivability & $\begin{array}{l}\text { Does the ERP system preserve and protect its past records for } \\
\text { future references? }\end{array}$ \\
\hline \multirow[t]{2}{*}{ Maintainability } & Modularity & $\begin{array}{l}\text { Is the ERP system composed of discrete components or } \\
\text { modules for easy usage? }\end{array}$ \\
\hline & Reusability & $\begin{array}{l}\text { Can the modules in ERP system be used to operate other } \\
\text { modules in the same ERP system? }\end{array}$ \\
\hline
\end{tabular}


E. Peters et al. / Advances in Science, Technology and Engineering Systems Journal Vol. 5, No. 2, 578-583 (2020)

\begin{tabular}{|l|l|l|}
\hline & Analyzability & $\begin{array}{l}\text { How fast does the ERP system diagnose or troubleshoot } \\
\text { problems? }\end{array}$ \\
\hline & Modifiability & $\begin{array}{l}\text { Can the ERP system be changed or updated without } \\
\text { introducing bugs or degrading the existing standards? }\end{array}$ \\
\hline & Testability & $\begin{array}{l}\text { Does ERP system provide test criteria for testing certain } \\
\text { actions or changes in the system? }\end{array}$ \\
\hline Portability & Adaptability & $\begin{array}{l}\text { Can ERP system be moved or transferred easily to other } \\
\text { environment or platform without any glitches? }\end{array}$ \\
\hline & Installability & $\begin{array}{l}\text { Cow quickly and easily can ERP system be configured? } \\
\text { the same environment? }\end{array}$ \\
\hline & Replaceability &
\end{tabular}

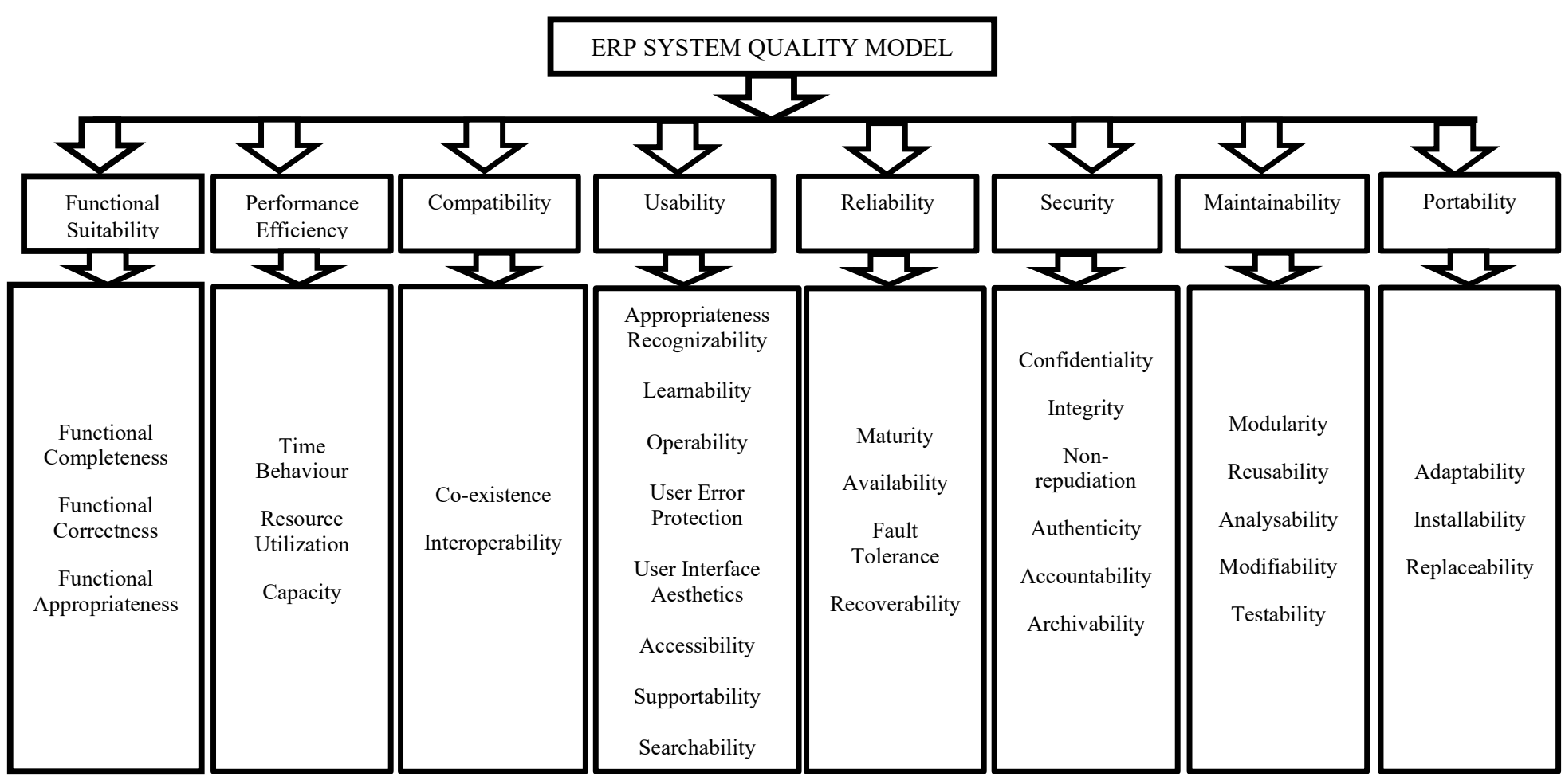

Figure 1: ERP System Quality Model

\section{Conclusion}

A new quality model for evaluating the quality of ERP systems in higher education institutions has been proposed. The model's quality factors and sub-factors were based on the ISO 25010 standard. To our knowledge, this model is first of its kind proposed for the evaluation of ERP systems in HEIs. The study brings to forth three important contributions which include the comparison of two popular software quality models, identification of quality factors of ERP systems and the ISO 25010 standard as a base for the new quality ERP systems model in HEIs. Further studies to establish the relationships between the quality factors and subfactors of this model in HEIs will be presented in the next paper. The results of the further study will enable us to understand the interrelation and the influence that these sub-factors would have on the quality factors of this model.

\section{Conflict of Interest}

The writers of this document declare no conflict of interest.

\section{Acknowledgment}

The writers of this piece of work want to acknowledge the grace and mercy of God for His enablement, continual guidance and assistance towards the completion of this document. We are also grateful to all those who one way or the other contributed to the success of this research study.

\section{References}

[1] Ghuman, K.; Chaudhary, S. (2012) "Incorporation of ERP in Educational Institutions: An Empirical Study", International Conference on Technology and Business Management, pp. 318-324

[2] Rabaa'i, A.; Bandara, W.; Gable, G. (2009a) "ERP systems in the higher education sector: a descriptive study", Proceedings of the 20th Australasian Conference on Information Systems, pp. 456-470

[3] Swartz, D. and Orgill, K. (2001). "Higher Education ERP: Lessons Learned", EDUCAUSE Quarterly, (2), pp. 20-27.

[4] Allied Market Research, 2015

[5] Fahmy, S., Haslinda, N., Roslina, W. and Fariha, Z. (2012). "Evaluating the Quality of Software in e-Book Using the ISO 9126 Model”. International Journal of Control and Automation Vol. 5, No. 2. 
[6] Padayachee, I., Kotze P. and Van der Merwe, A. (2010). "ISO 9126 External Systems Quality Factors, Sub-Factors and Domain Specific Criteria for Evaluating E-Learning Systems", In Proceedings of SACLA Conference.

[7] Alrawashdeh, T.A., Muhairat, M., \& Althunibat, A., (2013) "Evaluating the Quality of Software in ERP Systems Using the ISO 9126 Model", International Journal of Ambient Systems and Applications (IJASA) Vol.1, No.1, March 2013

[8] Djouab, R. and Bari, M. (2016) “An ISO 9126 Based Quality Model for the e-Learning Systems", International Journal of Information and Education Technology, Vol. 6, No. 5, May 2016

[9] ISO/IEC TR 9126-4 (2004) "Software Engineering- Product Quality - Part 4: Quality in Use Metrics". International Organization for Standardization, Geneva, Switzerland.

[10] Peters, E., \& Aggrey, G. K. (2019a, March). "Evaluating the Effectiveness of ERP Systems in HEIs: A Proposed Analytic Framework". In 2019 International Conference on Computing, Computational Modelling and Applications (ICCMA) (pp. 40-45). IEEE.

[11] França, J.M.S., Soares, S. M. (2015). "SOAQM: Quality Model for SOA Applications based on ISO 25010", Proceedings of the 17th International Conference on Enterprise Information Systems (ICEIS-2015), pages 60-70

[12] Haoues, M., Sellami, A., Ben-Abdallah, H. and Cheikhi, L. (2017). "A guideline for software architecture selection based on ISO 25010 quality related factors", Int J Syst Assur Eng Manag (November 2017) 8(Suppl. 2):S886-S909

[13] Iqbal, H. and Babar, M. (2016). "An Approach for Analyzing ISO / IEC 25010 Product Quality Requirements based on Fuzzy Logic and Likert Scale for Decision Support Systems", International Journal of Advanced Computer Science and Applications, Vol. 7, No. 12

[14] ISO/IEC (2011). ISO/IEC 25010 - "Systems and Software Engineering Systems and Software Quality Requirements and Evaluation (SQuaRE)" System and Software Quality Models. Technical report. 